\title{
Alcohol Abuse in Later Life: Issues and Interventions for Counselors
}

\author{
Jane E. Myers \\ Carol E. Dice \\ Brian J. Dew
}

The authors discuss risk factors for late life alcohol abuse and characteristics that differentiate early- and late-onset abusers. Problems in identification, diagnosis, assessment, and treatment of older abusers are reviened. A case example illustrates the dynamics of effective treatment with this population.

"The substance abuse problem in older adults is a serious one ... [ranking] third among leading mental disorders in older Americans, accounting for 10 to 12 percent of those who receive services from mental health professionals" (Smyer \& Qualls, 1999, p. 212). Prevalence estimates of alcoholrelated problems among older adults range from $5 \%$ to $60 \%$ of older persons living independently (Marcus, 1993) and from 15\% to $44 \%$ of older persons living in institutional settings. A conservative estimate is that $10 \%$ of the older adult population experiences substance abuse problems, which typically are undiagnosed and untreated because of the tendency for all substance abusers to deny usage (Segal, Van Hasselt, Hersen, \& King, 1996). As the number of older Americans increases from the present 33 million to an estimated 70 million in 2030 (American Association of Retired Persons [AARP], 1996), it is likely that the number of older persons experiencing problems related to alcohol will also increase.

Although treatment success with older persons is comparable to that with younger substance-abusing populations (Blow, 1991), older adults with alcohol problems are far less likely to receive professional care (King,

Jane E. Myers is a professor, and Carol E. Dite is a doctoral candidate, both at the University of Narth Carolina at Greensboro. Brian). Dew is president of In Speak Communitations, Greensboro. North Carolina. Correspondence regarding this article should be sens so Jane E. Myers, Department of Counseling and Educational Development, PO Box 26171. The University of North Carolina at Greensboro, Greensboro, NC 27402-6171 (e-mail: jemyers@uncg.edu). 
Van Hasselt, Segal, \& Hersen, 1994). In fact, only 15\% of older adults with alcohol problems receive adequate treatment (Parette, Hourcade, \& Parette, 1990). Treatment is complicated by underdiagnosis or misdiagnosis of alcohol problems in older individuals, which may be either ignored by health care providers or hidden by older people and their families (Miller, Belkin, \& Gold, 1991).

Effective intervention with older adult abusers requires different strategies for identification, diagnosis, assessment, and treatment than are commonly used with younger abusers (Dupree \& Schonfeld, 1996; Schonfeld \& Dupree, 1991). Counselors who work with older individuals are likely to encounter older substance abusers, and thus may benefit from knowledge of these differences, as well as skill in effective intervention strategies to help older persons experiencing problems with abuse. In this article, we (a) provide a brief overview of the physiological effects of alcohol consumption in older persons; (b) discuss characteristics of older substance abusers; (c) examine problems that arise in accurately identifying and diagnosing alcohol abuse in the older population; (d) discuss assessment and treatment strategies that have been used with older people and the implications for counselors; and (e) present a case example from the third author's practice to demonstrate late-life substance abuse disorders.

\section{PHYSIOLOGICAL EFFECTS OF ALCOHOL IN LATER LIFE}

Older persons experience changes and declines in every body system, making them more prone to infectious diseases and less able to tolerate stress (Saxon \& Etten, 1994). Although acute and often curable medical conditions are common earlier in life, older persons frequently experience chronic disease states that require medical management and result in progressive disability (Ferrini \& Ferrini, 1992). Both diagnosis and treatment are complicated because multiple problems often occur simultaneously, thus requiring many older adults to consume multiple medications (HHS Inspector General, 1989). Older individuals experience adverse effects from alcohol because of medication interactions as well as the aging process itself. It has been estimated that about half of all the drugs older people take can interact with alcohol (Schmall, Gobeli, \& Stiehl, 1989), with adverse reactions ranging from temporary behavioral changes to life-threatening acute reactions (King et al., 1994). In older individuals, normal age-related decreases in lean body mass and fluid volume and declines in kidney and liver functions mean that alcohol is less readily metabolized and that blood alcohol concentration, even from relatively small amounts of alcohol, may reach toxic levels (Ruppert, 1996).

The medical conditions that can result from chronic drinking at any age, including liver disease, pancreatitis, and cardiovascular disorders, may 
affect virtually every part of the body (National Institute on Alcohol Abuse and Alcoholism [NIAAA], 1991). The effects of alcohol on brain functioning are of particular concern with older people, because decreases in cognitive function are associated with the aging process itself and with several cognitive disorders found primarily in older individuals. Normal, age-related physiological changes sometimes make the effects of these medical conditions more severe among older than younger individuals, thus making differential diagnosis more complex (King et al., 1994; Marcus, 1993). Effective treatment requires accurate assessment, which in turn requires an understanding of the unique characteristics of older alcohol abusers.

\section{CHARACTERISTICS OF OLDER ALCOHOL ABUSERS}

Various factors have been identified that predispose older people to substance abuse, including personal, social, and familial concerns. In addition, three types of older problem drinkers have been identified: early onset, late onset, and intermittent (Staples, 1989). The interaction of predisposing factors with the type of abuse results in the need for a variety of treatment approaches.

\section{Personal Risk Factors}

The literature on older problem drinkers documents several personal risk factors for alcoholism, including sex, marital status, and use of avoidance coping strategies (Laforge, Nirenberg, Lewis, \& Murphy, 1993; Moos, Brennan, Fondacaro, \& Moos, 1990). Many studies show that older men tend to drink more heavily and have more difficulties with problem drinking than do older women (Laforge et al., 1993). Marital status has been shown to be a risk factor in cross-sectional studies that controlled for sex, with married older persons having fewer drinking problems (Moos et al., 1990). Gomberg (1995) noted that older women who are problem drinkers are more likely to be widows, users of psychoactive drugs, and diagnosed with depressive mood disorder.

Older individuals experience a variety of life changes, stresses, and losses that may affect their mental health (Duffy, 1999). Those who use avoidance coping strategies in responding to these experiences are at greater risk for problem drinking (Brennan, Moos, \& Mertens, 1994). Older problem drinkers report more depressive symptoms than do other older persons and have a greater incidence of preexisting psychiatric conditions (King et al., 1994). Depression and alcoholism are major precipitating factors for suicide in older people (Osgood, 1991), and both may be caused by, and contribute to, a lack of effective social support for older substance abusers. 


\section{Social Risk Factors}

Gurnack (1997) identified several social risk factors for problem drinking, including isolation, inadequate social support systems, and marital disruption. Isolation may result from factors such as disability, role loss because of retirement, or separation from family and friends because of geographic moves or deaths (Myers, 1999). Although increased leisure time has been suggested as a predisposing factor for late-life alcohol abuse (Ruben, 1992), drinking in response to specific late-life stressors, or reactive drinking, has not been uniformly established as a risk factor (Atkinson, 1990).

It is more likely, given the importance of social support over the life span (Ulione, 1996), that it is the mediating influence of social support that contributes to the risk for abuse. Older individuals with strong social support networks are less likely to use alcohol to cope with the stresses of later life (Bartels, Mueser, \& Miles, 1997; Brennan \& Moos, 1990), and more likely to come to the attention of health care providers if alcohol consumption becomes a concern. Family members are one element of social support networks, and their support may be positive, negative, or both.

\section{Family Risk Factors}

Past personal or family history of alcohol abuse has been strongly correlated with alcohol abuse in later life (Atkinson, Tolson, \& Turner, 1990; Brennan et al., 1994). A partial explanation for this finding involves consideration of early onset alcohol abuse, which is discussed later in this article, in which an individual may be a chronic alcohol abuser in his or her younger years and continue this behavior into later life. For both early-and late-onset problem drinkers, disharmony in family relationships can contribute to alcohol abuse as a coping mechanism (Dupree \& Schonfeld, 1996).

For early-onset problem drinkers, adult children have often experienced painful and dysfunctional family situations. The problem drinker may be looked at as the perpetrator of the painful family situation (Amodeo, 1990), and both family members and other caregivers may experience hostility toward the older problem drinker. This in turn may lead to ineffective and patronizing treatment of the problem drinker by the caregiver and family members and increased stress for the older abuser, leading to a continuing cycle of substance abuse. This cycle can represent the continuation of dysfunctional patterns of relating in situations of early-onset drinking patterns, or it may develop when late-onset drinking becomes an issue.

\section{Types of Problem Drinkers}

About two thirds of older problem drinkers are classified as early-onset drinkers, indicating that these individuals started having problems with drinking before they were 50 years old (AARP, 1992). Early-onset problem drinkers have more physical and mental health problems, show greater 
deficits in psychological and social functioning, and have poorer prognoses than do late-onset problem drinkers (Atkinson et al., 1990; Hoffman, 1995; Schonfeld \& Dupree, 1991). Late-onset problem drinkers, whose problem drinking started after age 50 , are less likely to have a familial history of alcoholism and are also less likely to have a rapidly deteriorating medical condition as are early-onset problem drinkers. Late-onset problem drinkers are also less likely to exhibit depression or anxiery than early-onset problem drinkers (Schonfeld \& Dupree, 1991). The pattern of alcohol abuse for late-onset drinkers usually can be related to one or more of the major stresses accompanying the aging process, such as grief and loss, loneliness, social isolation, retirement, increased health problems, and lowered income (McMahon, 1992; Widner \& Zeichner, 1991). When such patterns can be identified, treatment options may be more clearly specified. However, the existence of mulriple comorbidity typically complicates both diagnosis and treatment of older abusers (Blow, 1991).

\section{PROBLEMS IN IDENTIFICATION OF LATE-LIFE ALCOHOLICS}

Identification of older alcoholics is crucial for preventing adverse medical consequences and for designing treatment for potential psychiatric consequences such as cognitive impairment, sleep disturbance, and psychotic or violent behaviors. Diagnosis is complicated by personal characteristics of older abusers, family reactions, and comorbidity of physical and mental health concerns.

Alcoholism among older adults tends to be a "hidden" problemhidden both by the older individuals themselves and by their family and other caregivers. Few persons of any age admit to substance abuse problems. It is, therefore, no surprise that denial is common among older alcohol abusers, for whom predominant cohort values suggest that alcohol use may be immoral (Miller et al., 1991). Older people can easily rationalize that age-related problems, not alcohol, are causing their confusion, lack of balance, and other symptoms. Older individuals who live alone, in particular, may find it is easy to conceal their drinking pattern and its effects on their daily functioning.

Denial also extends to the family members and caregivers of older persons, who may have difficulty recognizing or admitting the problem. Caregivers may actually encourage drinking behaviors as "one of the few pleasures" left to the older person (Miller et al., 1991). Even when family members recognize that a significant drinking problem exists, they may deny the problem or inadvertently collude with the problem drinker because of feelings of shame or embarrassment (Ticehurst, 1990). Families also may choose not to seek treatment because they have unduly negative expectations about the value of treatment (Miller et al., 1991) or because 
they assume that the older person is so near the end of his or her life that treatment would make little difference.

The differential diagnosis of problem drinking in older people can be extremely difficult because many of the classic signs of alcoholism, such as memory loss, confusion, and loss of coordination leading to falls, are also associated with normal aspects of the aging process (Huntington, 1990; King et al., 1994). Alcoholism symptoms are also shared with symptoms of common medical conditions among older adults, including dementia, depression, and anxiety. These symptoms may be caused by malnutrition, dehydration, medication interactions, and other conditions that are commonly found among members of the older population.

Affective disorders such as depression, anxiery, and cognitive difficulties can lead to alcohol abuse, or they can result from alcohol abuse. In fact, alcohol and drug dependence are capable of producing virtually any psychiatric syndrome (Miller et al., 1991). Attempts at differential diagnosis, therefore, typically include an examination of patterns of usage, but detecting such patterns among older adults may be hard because corroboration from significant others can be difficult or even impossible to obtain (Beresford, Blow, Brower, Adams, \& Hall, 1988). A variety of assessment cools have been used to screen older adults for alcohol abuse, with varying rates of success.

\section{ASSESSMENT OF ALCOHOL DEPENDENCE IN OLDER PEOPLE}

Gurnack (1997) and Blow (1991) provide thorough reviews of screening instruments for late-life alcohol abuse. These include paper-and-pencil measures as well as clinical assessment questionnaires. These instruments should be used in conjunction with other assessment measures, because no screening instrument has been sufficiently validated for use by itself in assessing substance abuse in older persons (Atkinson et al., 1990).

The Michigan Alcoholism Screening Test (MAST; Selzer, 1971) and the Cut Down, Annoyed, Guilty, Eye Opener (CAGE) questionnaire (Mayfield, McLeod, \& Hall, 1974) are the most frequently used screening tools for alcoholism (Tabisz et al., 1991). Both of these instruments have proven to be reliable and valid in derecting alcoholism in older adults (Bush, Shaw, Cleary, Delbanco, \& Aronson, 1987; Willenbring, Christensen, William, \& Rassmussen, 1987). A geriatric version of the MAST, the MAST-G, is also available (Blow, 1991).

Positive answers to two or more of the questions on the CAGE indicate the presence of problems with alcohol in the general population (Maxmen \& Ward, 1995). Buchsbaum, Buchanan, Welsh, Centor, and Schnoll (1992) validated the CAGE in a study of older medical outpatients who had alcohol problems and found a cutoff score of one to be a more sensitive indicator of drinking 
problems. Once a possible problem has been identified through such a screening, a clinical assessment is needed (Maxmen \& Ward, 1995). This assessment should include a thorough physical and medical history, including patterns of usage of any abusable substances, adverse consequences usage, prescribed and over-the-counter medication usage, social and occupational supports and functioning, the presence or absence of common symptoms of substance abuse, a thorough physical examination, and multiple laboratory tests. Family or caregiver corroboration is essential for determining the accuracy of the information provided by the older drinker. Older problem drinkers cannot be adequately treated in the absence of an accurate diagnosis; thorough assessment of the extent of the drinking problem; and evaluation of the extent of adverse physical, mental, and psychological effects of the problem drinking. Even with accurate assessment, however, treatment can be difficult.

\section{BARRIERS TO TREATMENT OF OLDER ALCOHOLICS}

The major barriers to effective treatment for older alcoholics include denial on the part of the older individual, family, friends, and caregivers, and bias among health care providers. Although family members or friends may recognize and identify the signs of alcoholism, the older alcoholic may not recognize or admit to a problem (AARP, 1994). With older individuals, excuses can seem particularly reasonable and rational. Examples include, "I need a little something to help me sleep," "I'm all alone now, so who cares," and "I'm going to die of something anyway, so why not enjoy it" (Amodeo, 1990). As noted earlier, families may be reluctant to seek treatment because of shame and embarrassment, as well as denial of the problem.

Marion and Stefanik-Campisi (1989) noted several reasons that health care providers fail to refer older alcohol abusers for treatment. Referral barriers include treating the underlying precipitating factors such as depression and grief rather than treating alcoholism as a primary illness, nurturing the philosophy that treatment for alcoholism and confronting the denial is worse than the disease of alcoholism, believing that the patient should "hit bottom" and request help before providing treatment, and viewing the complications of alcoholism in older adults as so overwhelming that there is no use in initiating treatment.

Family, caregivers, and health service providers may share negative outcome expectations for treatment of the older abuser, even though treatment outcomes may be equally as or more positive for older individuals than for other age groups (Defour \& Fuller, 1995). A positive prognosis is especially applicable to late-onset drinkers (Liberto et al., 1992). On the other hand, problem drinkers who seek treatment also tend to be the most poorly functioning abusers (Brennan et al., 1994), thus multiple approaches to treatment may be required. 


\section{TREATMENT FOR OLDER ALCOHOLICS}

A variety of recommendations for treatment of older alcoholics have been proposed (Schonfeld \& Dupree, 1995). Dupree and Schonfeld (1999) recommended using a cognitive-behavioral approach to modify late-life drinking patterns. These interventions may be used in individual as well as group settings. Liberto et al. (1992) noted the paucity of research on the benefits of self-help groups, individual therapy, and family interventions for older substance abusers, citing instead support for traditional substance abuse group treatments for older problem drinkers. However, a comparison of two inpatient programs for men revealed that the treatment program with the goal of developing patient self-esteem and peer relationships was more successful than the traditional group approach of confronting past difficulties (Kashner, Rodell, Ogden, Guggenheim, \& Karson, 1992). Although one study found no age differences related to completion of treatment (Brewer, Zawadski, \& Lincoln, 1990), Stoddard and Thompson (1996) emphasized the need for interventions that address both substance abuse and aging concerns and that involve aggressive recruitment of family members to participate in treatment programs.

A consensus panel of experts on alcohol abuse in later life concluded that treatment options for older substance abusers should use the least intensive treatment options first, noting that

these initial approaches, which can function either as pretreatment strategy or treatment itself, are brief intervention, intervention, and motivational counseling. They may be sufficient to address the prob$\mathrm{lem}$; if not, they can help move a patient toward specialized treatment. The Consensus Panel recommends that every reasonable effort be made to ensure that older substance abusers, including older problem drinkers, enter treatment. Brief intervention is the recommended first step, supplemented or followed by intervention and motivational interviewing. Because many older problem drinkers are ashamed about their drinking, intervention strategies need to be nonconfrontational and supportive. (Blow, 1991, p. xix)

The Panel also recommended six specific features that should be incorporated into any treatment program for older alcohol abusers. These include

(1) age-specific group treatment that is supportive and nonconfrontational and aims to build or rebuild ... self-esteem; (2) a focus on coping with depression, loneliness, and loss ....; (3) a focus on rebuilding the client's social support network; (4) a pace and content of treatment appropriate for the older adult; 
(5) staff members who are interested and experienced in working with older adults; and (6) linkages with medical services, services for the aging, and institutional settings for referral into and out of treatment, as well as case management. (Blow, 1991, p. xxi)

In addition, the recommendations include suggestions for treatment of older individuals in age-specific settings, creating a culture of respect for older individuals, emphasizing a holistic approach to treatment, maintaining flexibility in the treatment plan, and adapting treatment protocols in reponse to gender issues. The application of these recommendations in counseling with an older alcoholic is described in the following case example, taken from the clinical practice of the third author.

\section{CASE EXAMPLE}

William H. is a 68-year-old, married, Caucasian man who was admitted to a local behavioral health care program that specialized in the treatment of alcohol-related problems. The client admitted to drinking approximately "a fifth [0.757 liter] of bourbon per day" in addition to consuming three to five beers nearly 5 days each week. The client acknowledged an increase in his drinking following a "very difficult time" that included retirement from work and the death of his mother. He denied current or past usage of any additional mood-altering substances.

William was referred by his primary physician following the onset of physical symptoms (e.g., tremors, irregular heartbeat), legal difficulties associated with his second driving while intoxicated (DWI) arrest in less than 2 years, and continued encouragement from his wife and children. His wife of 44 years had contacted his physician after witnessing several falls that resulted in severe bruising to his left upper torso and left eye. His four children had expressed concern after returning from a family vacation during which the client daily consumed large amounts of alcohol.

The client initially seemed to be in denial about problems related to his alcohol consumption. During the intake and screening interviews, the client denied that his medical problems were associated with his drinking. In addition, he initially declared that he had not been drinking before his second DWI arrest, although his medical chart reported a blood alcohol level of .24, three times the state's legal limit. In fact, during the screening process, the client stated, "men at my age are not alcoholics." Although he originally denied problems related to his drinking, the client did agree to enter the residential treatment program. Within 4 hours of his admittance, a psychosocial assessment was completed that thoroughly examined his history of alcohol consumption, family history of substance abuse, work 
history, and leisure habits. In addition, screenings for sexual abuse, sexual dysfunction, and depression were administered. From the information collected during the intake, screening, and psychosocial processes, it was determined that successful treatment would include four components: psychoeducation, group therapy, family involvement, and aftercare planning.

The treatment plan for this client included enhancing his understanding of certain aspects of alcoholism. In particular, the client participated in lectures that addressed the definition, prevalence, and the etiology of substance abuse and dependence. Medical professionals and individuals in recovery were invited to speak about the physical and physiological ramifications of alcoholism. This client's treatment plan specifically addressed his multiple losses by encouraging him to participate in a presentation on grief and loss, read pamphlets specifically targeted toward older adults and loss, and watch a video collection on grief (produced by Elizabeth Kubler Ross). The client was also encouraged to discuss his multiple experiences with grief within both an individual and group context.

This client was encouraged to participate in a variety of group opportunities. He was immediately placed in a daily coeducational therapy group that included individuals of diverse ages some of whom were other older adults. The client was encouraged to share with other group members his experiences with grief and loss. Sadness about his mother's death and fear about his own mortality were identified as significant "triggers" to drink and were shared by several members of the group. The client also participated in a same-sex group. Issues related to masculinity, communication, and difficulty with vulnerability were particularly relevant to this client. In addition, the client participated in a leisure-skill-building group. This opportunity allowed him to examine his leisure activities and develop a behavioral modification plan that included additional exercise and recreational activities.

An important facet of treatment of any addiction is addressing the impact on the family. As a result, this client's treatment team determined that his family must be an active part of his recovery. The client's wife and children were encouraged to participate in several programs. First, his family was encouraged to attend the weekly psychoeducational "Family Program" so that they could learn about such topics as anger and communication, medical aspects of addiction, and grief and loss. Second, following his discharge from treatment, the client and his wife and children returned to participate in four family sessions that addressed the progress and the needs of both the client and individual family members. Third, the client's family was encouraged to attend local Al-Anon meetings, twelve step fellowships targeted at friends and family of alcoholics.

Before completing treatment, this client participated in a 1-hour aftercare planning session. During this meeting, the client developed a behavioral 
contract that outlined his plans for continued sobriety. In particular, the client identified the importance of attending Alcoholics Anonymous meetings in his community. He specifically targeted meetings that included a large proportion of older adults. He also agreed to volunteer as a driver for individuals who had no transportation to meetings. Furthermore, he agreed to participate in weekly counseling sessions following discharge from the treatment facility. He contacted a recommended therapist that was familiar with alcohol addiction and scheduled the initial appointment during the aftercare planning session.

Using the multifaceted treatment approach, which combined psychoeducation, group therapy, family involvement, and aftercare planning, resulted in William $\mathrm{H}$. achieving more than 4 years of sobriety. When reminded of his comment, "men at my age are not alcoholics," William H. stated, "I am lucky to be alive; most men at my age who are alcoholics are 6 feet under. We need to do more to reach out to ALL of us that struggle with this problem."

\section{CONCLUSION}

Alcohol abuse among older persons is a significant personal, familial, and social concern. Although the differential diagnosis of alcohol abuse and many of the common diseases and disabilities of later life is difficult, accurate assessment remains a precursor to effective treatment planning. The prognosis for late-onset alcoholics, in particular, is good. Multifaceted approaches to treatment have the potential to be effective, especially when combined with what Blake (1990) suggested-a strong sense of optimism on the part of the counseling that this client can and will be helped successfully. Additional research is needed to determine the types of older clients most amenable to intervention and the specific types of interventions most appropriate for both early and late onset older drinkers.

\section{REFERENCES}

American Association of Retired Persons (AARP). (1992). Under the influence [Brochure]. Washington, DC: Author.

American Association of Retired Persons (AARP). (1994). Alcohol abuse among older people [Brochure]. Washington, DC: Author.

American Association of Retired Persons (AARP). (1996). A profile of older Americams: 1996 [Brochure]. Washington, DC: Author.

Amodeo, M. (1990). Treating the late life alcoholic: Guidelines for working through denial integrating individual, family, and group approaches. Journal of Geriatric Psychiatry, 23, 91-105.

Atkinson, R. M. (1990). Aging and alcohol use disorders: Diagnostic issues in the clderly. International Psychogeriatrics, $2,55-72$.

Atkinson, R. M., Tolson, R. L. \& Turner, J. A. (1990). Late versus early onset problem drinking in older men. Alcoholism: Clinical and Experimental Research, 14, 574-579.

Bartels, S. J., Mueser, K. T., \& Miles, K. M. (1997). Functional impairments in elderly patients with schizophrenia and major affective disorder living in the cornmunity: Social skills, living skills, and behavior problems. Behavior Therapy, 28, 43-63. 
Beresford, T. P., Blow, E. C., Brower, K. J., Adams, K. M., \& Hall, R. C. W. (1988). Alcoholism and aging in the general hospital. Psychosomatics, 29, 61-72.

Blake, R. (1990). Mental health counseling and older problem drinkers. Journal of Mental Health Counseling, 12, 354-367.

Blow, F. (1991). Michigan Alcoholism Screening Test-Geriatric version (MAST-G). Ann Arbor, MI: Universiry of Michigan Alcohol Research Center.

Brennan, P. L., \& Moos, R. H. (1990). Late life stressors, social resources, and late-life problem drinking. Psychology and Aging. 5. 491-501.

Brennan, P. L., Moos, R. H., \& Mertens, J. R. (1994). Personal and environmental risk factors as predictors of alcohol use, depression, and tteatment-seeking: A longitudinal analysis of late-life problem drinkers. Journal of Subssance Abuse, 6, 191-208.

Brewer, L. G., Zawadski, M. L., \& Lincoln, R. (1990). Characteristics of alcoholics and codependents who did and did not complete treatment. The International Journal of the Addictions, 25, 653-663.

Buchsbaum, D. G., Buchanan, R. G., Welsh, J., Centor, R. M., \& Schnoll, S. H. (1992). Screening for drinking disorders in the elderly using the CAGE questionnaire. Journal of the American Geriatrics Society, 40, 662-665.

Bush, B., Shaw, S., Cleary, P. Delbanco, T. L., \& Aronson, M. D. (1987). Screening for alcohol abuse using the CAGE questionnaire. The American fournal of Medicine, 82, 231-235.

Duffy, M. (Ed.). (1999). Handbook of counseling and pychosherapy with older adults. New York: Wiley.

Dupree, L. W., \& Schonfeld, L. (1996). Substance abuse. In M. Hersen \& V. B. Van Hasselt (Eds.), Pychological treatment of older adults (pp. 281-297). New York: Plenum.

Dupree, L. W., \& Schonfeld, L. (1999). Management of alochol abuse in older adults. In M. Duffy (Ed.). Handbook of counseling and psychotberapy with older adults (pp, 632-650). New York: Wilcy.

Ferrini. A. F., \& Ferrini, R. L. (1992). Health in the later years (2nd ed.). Dubuque, IA: Brown \& Benchmark.

Gomberg, E. J. (1995), Older women and alcohol: Use and abuse. In M. Galanter (Ed.), Recent developments in alcoholism, VoL. 12. Alioholism and women (pp, 61-79). New York: Plenum.

Gurnack, A. M. (Ed.). (1997). Older adults misase of alcohol, medicines, and other drugs: Research and practice issues. New York: Springer.

HHS Inspector General, U.S. Department of Health and Human Services. (1989). Expenses incurred by Medicare beneficiaries of prescription drugs. Washington, DC: U.S. Department of Health \& Human Services.

Hoffman, A. (1995). Alcohol problems in elder persons. In M. Stanley (Ed.). Gerontological Nursing. Philadelphia: Davis.

Huntington, D. D. (1990). Home care of the elderly alcoholic. Home Healthcare Nurse, 8, 26-32.

Kashner, T. M., Rodell, D. E., Ogden, S. R., Guggenheim, F. G., \& Karson, C. N. (1992). Ourcomes and costs of rwo VA inparjent trearment programs for oldes actobolic patients. Hospisal and Community Psychiasry, 43, 985-989.

King, C. J., Van Hasselt, V. B., Segal, D. L., \& Hersen, M. (1994). Diagnosis and assessment of substance abuse in older adults: Current strategies and issues. Addictive Behaviors, 19, 41-55.

Laforge, R. G., Nirenberg, T. D., Lewis, D. C., \& Murphy, J. B. (1993). Problem drinking, gender and stressful life events among hospitalized elderly drinkers. Behavior. Health, and Aging, 3, 129-138.

Liberto, J. G., Oslin, D. W., \& Ruskin, P. E. (1992). Alcoholism in older persons: A review of the literature. Hospiral and Community Psychiatry, 43, 975-984.

Marcus, M. T. (1993). Alcohol and other drug abuse in elders. Journal of ET Nursing. 20, 106-110.

Marion, T. R., \& Stefanik-Campisi, C. (1989). Perspectives in Psychiatric Care, 25(3-4), 32-35.

Maxmen, J. S., \& Ward, N. G. (1995). Essential psychopathology and its treatment (2nd ed.). New York: Norton.

Mayfield, D., McLeod, G., \& Hall, P. (1974). The CAGE questionnaire: Validation of a new alcoholism instrument. American Journal of Psychiatry, 131, 1121-1123.

McMahon. A. L. (1992). Alcoholism in the elderly. The Florida Nurse, 40, 8-9.

Milles, N. S., Belkin, B. M., \& Gold, M. S. (1991). Alcohol and drug dependence among the elderly: Epidemiology, diagnosis, and treament. Comprehensive Psychiatry, 32, 153-165.

Moos, R. H., Brennan, P. L., Fondacaro, M. R., \& Moos, B. S. (1990). Approach and avoidance coping responses among older problem and nonproblem drinkers. Prychology and Aging, 5, 31-40.

Myers, J. E. (1999). Adjusting to role loss and leisure in later life. In M. Duffy (Ed.). Handbook of counseling and psychotherapy with older adults (pp. 41-56). New York: Wiley. 
National Institute on Alcohol Abuse and Alcoholism. (1991). Alcohol research: Promise for the decade (DHHS Publication No. ADM-92-1990). Washington. DC: U.S. Government Printing Office.

Osgood, N. J. (1991), Psychological factors in late-life suicide. Special Issue: Suicide in the elderly. Crisis, 12(2), 18-24.

Parette, H. P., Hourcade, J. J., \& Parette, P. C. (1990). Nursing attirudes toward geriatric alcoholism. Journal of Gerontological Nursing. 16, 658-661.

Ruben, D. H. (1992). The elderly and alcohol and medication abuse, In C. E. Stout, J. L. Levitt, \&e D. H. Ruben (Eds.), Handbook for assessing and treating addictive disorders (pp. 216-235). Westport, CT: Greenwood.

Ruppert, S. D. (1996), Alcohol abuse in older persons: Implications for critical care. Critical Care Nursing Quarterly, 19, 62-70.

Saxon, S. V., \& Etten. M. J. (1994). Physical change and aging: A guide for the helping professions (3rd ed., rev.). New York: Tiresias.

Schmall, V. L., Gobeli, C. L., \& Stichl, R. E. (1989, September). Alcohol problems in later life (BuIletin No. PNW 342). Pacific Northwest Extension Service: Oregon State University, School of Education.

Schonfeld, L., \& Dupree, L. W. (1991). Antecedents of drinking for early- and late-onset elderly alcohol abusers. Journal of Studies on Alcohol, 52, 587-592.

Schonfeld, L.. \& Dupree, L. W. (1995). Treatment approaches for older problem drinkers. International fournal of the Addictions, 30, 1819-1842.

Segal, D. L.. Van Hassclt, V. B.. Hersen, M., \& King, C. \{1996\}. Treatment of subsrance abuse in older adults. In J. R. Cautela \& W. Ishaq (Eds.), Contemporary issues in behavior therapy: Improving the human condirion. New York: Plenum.

Selzer. M. (1971). The Michigan Alcoholism Screening Test: The quest for a new diagnostic instrument. The American Journal of Psychiatry. 127. 89-94.

Smyer, M. A., \& Qualls, S, H. (1999). Aging and mental health. Malden, MA: Blackwell.

Staples, P. (1989), Alcohol-related problems of alder persons (ED325789). W/ashingron, DC: ER.TC,

Stoddard, C. E., \& Thompson, D. L (1996). Alcohol and the elderly: Special concerns for counseling professionals. Alcaholism Treatment Quarterly, 14(4), 59-69.

Tabisz, E., Badger, M., Meatherall, R., Jacyk, W. R., Fuchs, D., \& Grymonpre, R. (1991). Identification of chemial abuse in the elderly admitted to emergency. Clmical Gerontolngist, 1/, 27-38.

Ticchurst, S. (1990). Alcohol and the clderly. Australian and New Zealand Journal of Psychiatry, 24. $252-260$.

Ulione, M. S. (1996). Physical and emotional health in dual-earner families. Family and Community Health, 19, 14-20.

Widner, S., \& Zeichner, A. (1991). Alcohol abuse in the elderly: Review of epidemiology research and treatment. Clinical Gerontologist, 11, 3-18.

Willenbring, M. L., Christensen, K J., William, W. D., \& Rassmussen, R. (1987). The lifetime drinking history and the M.A.S.T. Journal of Studier on Alcohol, 35, 864-869. 